\title{
A construção de uma agenda para a saúde bucal coletiva
}

\section{Building an agenda for collective oral health}

Jorge Cordón 1

1 Departamento de Odontologia,

Universidade de Brasília. SQS 316, bloco C, apto. 103. Brasília, DF

70387-030, Brasil.

jcordon@persocom.com.br

\begin{abstract}
After visiting 14 cities from Brazil where important efforts to improve the SUS (Unified Heal th System) were being made, , the researcher used his main findings to propose a participant agenda-building process for collective oral health, integrated to the new scope of collective health at the municipal level. He notes the strategic role health professionals can play in a new historical proposal for Brazilian society.

Key words Oral Health; Public Health Dentistry; Public Health
\end{abstract}

Resumo Após visitar 14 ci dades do Brasil, onde se realizam esforços importantes para implementar o SUS, o pesquisador utiliza os princi pais achados para propor a construção participante de uma agenda de saúde bucal col etiva, que se integra à nova dimensão da saúde coletiva em nível municipal. Anota o papel fundamental de mediação que os trabalhadores da saúde podem realizar no projeto histórico da sociedade brasileira.

Palavras-chave Saúde Bucal; Odontologia em Saúde Pública; Saúde Pública 


\section{Introdução}

O processo de consolidação institucional do Sistema Único de Saúde requer uma reflexão sobre o seu significado político eideológico, na medida que representa um instrumento de melhoria das condições de vida da população brasileira, com a possibilidade histórica de vir a satisfazer as necessidades objetivamente expressas pela sociedade e não unicamente como uma "mera aspiração popular". Falta encontrar as formas político-operacionais para sua consolidação.

Este trabalho pretende propor, para discussão, al guns caminhos, especialmente na construção social da saúde bucal nos espaços sociais brasileiros onde se trava uma luta entre a concepção do mundo como totalidade social, integral e integrada nos processos individuais, grupais e coletivos e a visão funcional e acomodada ao sistema de manutenção da hegemonia da causa social das atuais condições de vida, o individualismo e os princípios neoliberais de governo.

Para aprofundar o problema, foi estudado o marco conceitual da reforma sanitária e do SUS, cujos elementos teórico-metodológicos constituíram oficinas construtivas de conhecimento que se manifestaram em 14 espaços sociais do Brasil (Cordón, 1996), através de visitas aos processos históricos que se realizam nos espaços - territórios de Porto Alegre (RS), Curitiba (PR), São Paulo (SP), Santos (SP), Belo Horizonte (MG), Ipatinga (MG), Timóteo (MG), Olinda (PE), Recife (PE), Camaragibe (PE), Fortaleza (CE), Icapuí (CE) e Natal (RN), acompanhando também movimentos em saúde bucal que se desenvolvem em Brasília, no Distrito Federal.

Nestes espaços sociais as diferentes correntes ideológicas travam fortes discussões teóricas, particularmente sobre a coerência de suas práticas, como estruturantes das idéias dominantes no esforço de avançar na construção do SUS. O anterior permite negociações (Mendes, 1993, 1996) que inspiram processos teóricometodológicos e assumem diversas correntes de pensamento no mesmo processo e é nesta diversidade concreta, onde o pesquisador encontrou as igualdades, as adversidades, as dificuldades, os avanços, os estancamentos e os sucessos, dentro do que poderia chamar-se de "proposta para uma saúde bucal coletiva" ou "uma agenda para a saúde bucal coletiva", para ser discutida como hipótese no trabalho crítico da prática de um determinado saber no complexo tecido social brasileiro.

Foram encontradas formas diversas de perceber a realidade e encontrar as soluções aos problemas de saúde bucal, o que vem ratificar a importância do trabalho local, municipal, da descentralização, da aceitação da pluralidade de concepções e o respeito pelos processos que dependem da história, da cultura e organização da coletividade.

Vida saudável para todos significa universal idade na atenção em odontologia em saúde coletiva e especialmente no acesso a uma qualidade de vida melhor, mais solidária, eqüitativa e justa. O que também significa que a prática deve mudar do modelo de odontologia integral, com forte inclinação "giesiana" (Gies, 1926; Cordón, 1996) na formação acadêmica, para um modelo de abertura de espaços sociais para uma odontologia inserida integralmente na saúde, abordando de forma participante estes espaços sociais que permite a sociedade quando vista como totalidade social.

Sabe-se que o trânsito da experiência particular-concreta dos governos locais para os níveis superiores de gestão do Estado só poderá ocorrer com sucesso se os atores forem capazes de, além de conquistar a confiança da maioria da população por meio de governos capazes e bem-sucedidos, ser portador de uma nova vida moral e de uma nova dimensão ético-política da sua "práxis", esta capaz de desvinculá-la da visão "particular" e dos enfoques dogmáticos ao ensejo de aventuras ditatoriais (Genro, 1996).

Daí ser importante, para os governos locais, não só retomar as relações de solidariedade e fraternidade entre os atores do processo social, mas também compartilhar na práxis social, as relações econômicas cooperativas, da cultura e da ciência do novo mundo moderno, desenvolvendo uma postura crítica frente à gl obalização e unificação da forma de vida, desejada e praticada pelo poder do capital, exclusivamente para implementar seus interesses de dominação.

Logo, qualquer proposta de intervenção em saúde deve, como obrigatório, observar, apreender a realidade, em cada espaço social, para poder compreender o indivíduo, o cidadão e as redes sociais que se constroem, podendo, desta forma, definir as necessidades dos cidadãos, seus problemas e os processos coletivos de transformação do modelo de vida em sociedade para conseguir a saúde bucal. 


\section{O problema}

Tomando em consideração a história da odontologia no Brasil, existe a formulação ou construção de um modelo ou uma forma distinta de organização da prática odontológica: a prática da saúde bucal coletiva que se apresenta nos processos de luta dos espaços políticos que o sistema dominante permite, fazendo-se representar de diversas formas e conteúdos, que sintetizam uma prática de saúde.

Assim sendo, estima-se que existe uma práxis social, orgânica à construção de um modelo de saúde caracterizado pela universali dade, a eqüi dadee a integral i dade da atenção em saúde bucal, cujos agentes, formados com orientação ecológica, utilizam o método científico para conhecer estruturalmente as características epidemiológicas em que se dão os processos de saúde-doença bucal.

Que isto o fazem através de uma abordagem, mediação e intervenção social democrática e participante, que define as políticas de saúde bucal como fazeres concretos, para resolver os problemas de saúde-doença bucal integralmente, e integrados a um conjunto de problemas gerais que caracterizam as dificuldades de um espaço social determinado para desenvolver-se plenamente.

Significa também que a prática odontológica se organiza de tal forma que, consciente e agindo política e estrategi camente, consegue transferir, aplicar e gerir de forma co-responsável, os conhecimentos científicos e tecnológicos acumulados, os que somados ao saber popular, permitem realizar ações, objetivas e subjetivas, para resolver os problemas encontrados.

Significa intervir positivamente para a população total, com hierarquia e descentralização (rede única de serviços onde os agentes de saúde bucal se inserem de forma crescente em complexidade, de referência e acompanhamento à saúde), considerando todos os espaços sociais e seus respectivos movimentos, para que com ênfase coletiva, possa ser promovida uma qualidade de saúde bucal desejada pela sociedade, com prioridade pelas necessidades dos seus problemas mais abrangentes e educadora em todos seus momentos ou processos. $\mathrm{O}$ que em última instância, coloca a categoria odontológica orgânica ao projeto histórico de qualidade de vida e sociedade que a maioria dos brasileiros anseia.

Daí a importância da inserção da odontologia no SUS, como transformação de uma prática, que leva novos conceitos, conteúdos e formas de organização, criando novos vínculos entre os sujeitos históricos que entram como atores sociais no SUS (trabalhadores da saúde, diretores, acadêmicos e a população, todos em igualdade de condições para, de uma maneira mais radical e mais orgânica, intervir na solução das necessi dades da sociedade total, isto é, a construção de uma agenda para a saúde bucal coletiva, problema fundamental para a categoria neste momento histórico).

\section{A agenda para a saúde bucal coletiva}

Não basta mais democratizar os recursos e eleger ações prioritárias, isto é apenas pré-requisito para a adoção de uma nova ordem gerencial. Seguramente é necessária uma reforma administrativa em nível local e a busca de inovações e parcerias com a sociedade civil com ações que podem contribuir para o processo de transformação do Estado e consolidar uma estabilidade econômica que diminua a exclusão.

Desta forma é dever dos trabal hadores de saúde bucal proporcionar condições objetivas e subjetivas para que a família, os novos movimentos de bairro, ecológicos, étnicos, de gênero, esportivos e outros movimentos sociais tenham possibilidade de expressão na construção da saúde e portanto, na histórica condução do processo de evolução da sociedade brasileira.

O anterior significa que o novo trabalhador em saúde bucal deve dominar o método científico, saber reconhecer-se, biológica e socialmente, estudar de forma participante um espaço - território com a população, ser crítico, criativo e sobretudo acompanhar as nuanças do tecido social, as costuras necessárias para inter-relacionar esforços e aumentar sua possibilidade de sucesso no espaço social em que desenvolve sua atividade profissional.

Três ações fundamentais aparecem como medidas de uma prática de odontologia em saúde coletiva ao inserir-se no SUS como fundamentos no preparo de uma agenda de intervenção: 1) As ações de colaboração e atuação com relação à organização, capacitação e politização social; 2) As ações de promoção e manutenção da saúde e prevenção coletivas; e 3) As ações reabilitadoras do dano biossocial causado pelo sistema social.

Reconstruir ou reformar uma estrutura sanitária, um modelo de serviço não é tarefa fácil em qualquer espaço político-social, especialmente no Brasil (Cecílio, 1994), onde o Estado permanece voltado para o passado, intervencionista incompetente de gerir os espaços que têm ocupado; que abriga um corporativismo funcional, ainda mais forte na área da saúde, agasalha elites, convive com horizontes de de- 
senvolvimento econômico cada vez mais estreitos por uma globalização dos mercados, onde falta desempenho, porque não existe motivação política e social, tanto dos dirigentes, quanto dos trabalhadores da saúde; porque é incompetente de recompor um corpo de técnicos capazes de avaliar e atuar de forma estratégica na consecução de recursos e mais do que isso, não tem base social que apóie as propostas, por melhor preparadas que sejam.

Assim sendo, o anterior constitui um grande desafio porque envolve uma transformação das formas organizacionais (organização das práticas de saúde bucal) e portanto passar do modelo assistencial, paternalista e viciado, para um modelo de atenção à saúde, com co-responsabilidade, isto é, participante e democrático, é tarefa bastante complexa.

É possível realizar mudanças gradativas e continuadas (Cordeiro, 1996), com decisão política e sobretudo com apoio popular, estabelecendo novos vínculos ou relações entre governo, centro de saúde, estrutura sanitária e sociedade, sem escravizar espaços, mas abrindo os maiores espaços sociais que possam ser fonte de energia para conseguir resultados ou mudanças qualitativas, mensuráveis e conhecidas da própria população para que as faça próprias e sua representação das atuais relações mude para uma referência mais positiva do trabalho que se faz em saúde bucal coletiva.

Isto está sendo realizado e está dando certo, é um caminho que requer sobretudo humildade e capacitação política dos dirigentes para compreender o espaço social em que se trabaIha como uma totalidade social, contraditória, porém, única.

Sendo os processos de saúde/ doença bucal problemas de caráter essencialmente sóciopolítico, uma intervenção em saúde bucal coletiva, para a construção da agenda para resolver estes problemas, deve iniciar-se em termos de políticas sociais.

Foi demonstrado que o enfoque curativo e das doenças constitui uma visão estreita da realidade, imprópria e pouco econômica. Já o seu contrário amplia o espaço para um cenário social da saúde que não omite outras categorias da saúde (potenciais ou reais, profissionais ou não profissionais, legais ou não) mas, sobretudo, assume um trabalho intersetorial pela qualidade da vida. Daí que o novo cenário da SaúdeBucal Coletiva éa sociedade, a totalidade única e contraditória.

O principal e primeiro elemento da agenda dos trabalhadores em saúde bucal coletiva constitui então saber que o dentista sozinho não pode resolver os problemas, que requerem uma equipe de saúde bucal integrada à equipe de saúde do SUS. É esta a primeira estratégia a desenvolver por parte dos trabalhadores da saúde. Paralelamente, convencer a sociedade da necessidade das políticas e medidas sociais específicas e dos governos para colocar em discussão junto com a população, participando do processo de implantação e implementação destas políticas sociais.

Esta intervenção tem como base a abordagem do fator comum de risco integral para a promoção da saúde. “Uma abordagem baseada no fator do risco integrado poderá, com a combinação de adequado diagnóstico bucal e um alto nível de habilidades, promover a saúde geral através de saúde bucal" (Sheiham, 1992).

Esta resposta ao fator de risco comum na totalidade social constitui o desenvolvimento da abordagem da promoção da saúde e inclui o nível macropolítico do espaço - território, o envolvimento intelectual no diagnóstico e planejamento das estratégias, para resolver os principais problemas de saúde (agricultura, educação, saúde, cultura e lazer, trabalho e emprego, transporte, relações internacionais, habilitação e econômico) - e o nível micropolítico, o planejamento intersetorial e interdisciplinar, com a equipe de saúde que inclui professores, trabalhadores de saúde na atenção primária, representantes das redes e movimentos sociais, coordenando seus esforços no estudo e abordagem integral dos fatores comuns de risco dos problemas de saúde num processo participante de planejamento das estratégias e ações de promoção da saúde que estabelecem a agenda de saúde para o espaço-território e particularmente a agenda de saúde bucal .

Conclui-se que não adianta falar de agenda de saúde bucal coletiva para o Brasil, entretanto, podem ser apreciadas as experiências observadas, bem como a literatura internacional, numa proposta de agenda de saúde bucal, que discutida em nível macro, no Conselho Nacional de Saúde, pudesse ampliar as características próprias na sua implementação no nível local.

Não está demais repetir que a população deve participar de todo o processo de planejamento, desde o diagnóstico epidemiológico, participando da construção dos indicadores de satisfação social bucal (Cushing et al., 1986; Murray \& Wirse, 1975; Reisine, 1981) de situações-problema (Reisine, 1981; Sheiham \& Croog, 1981), para realizar o levantamento epidemiológico estrutural que permitirá estabelecer os fatores de risco comum na totalidade social e especificamente, à medida que se encontram na dieta e na sujeira bucal os fatores que 
têm a ver com os principais problemas específicos de saúde/ doença bucal : cáries dentária e doença periodontal.

Uma vez definidos os problemas, com distribuição do risco populacional, impõe-se a discussão da agenda de saúde bucal coletiva, inserida na agenda de saúde do espaço - território social, que inclui o acordo, a negociação das normas e princípios que devem orientar as ações de solução dos problemas no Conselho Local de Saúde. Esta espécie de contrato, de acordo de esforços mútuos e de ações participantes deve conseguir um consenso, numa síntese da discussão política, porque dela surgirão as principais ações gerais e locais para a totalidade social.

Uma vez definida esta agenda de saúde bucal coletiva, este esforço deve institucionalizarse nas metas e ações a curto, médio e longo prazo, considerando a urgência que a população tem na solução dos problemas de saúde/ doença bucal.

Desta institucionalização advém um planejamento participante da programação das ações e controle dos fatores de risco (açúcar, propaganda perniciosa, alimentos que introduzem açúcar na população como bebidas enlatadas, refrigerantes e outros, controle de sua produção através de vigilância à saúde bucal, vigilância na fluoretação da água de consumo humano, e a produção de alimentos com baixo teor de açúcar ou alternativos através de compostos naturais ou não açucarados).

Neste fator, o próprio estilo de vida constitui a variável mais importante na situação de saúde bucal e que tem a ver com o comportamento individual e coletivo, (Folha de São PauIo, 1996; Sheiham \& Croog, 1981) movido geralmente por comerciais de televisão, veiculados durante os programas voltados ao adolescente que sugerem e condicionam a ingestão de alimentos de caloria vazia - que contém energia, mas pouco ou nenhum nutriente - e tira-gostos ("snacks"), próprios para consumir-se fora das refeições, aderindo ao modernismo de "fast-food" especial mente ligado a refrigerantes, biscoitos, doces, balas, batatas fritas, bebidas isotônicas, cereais, cerveja, chocolate, hambúrguer, sorvete, pipoca e mai onese, entre outros.

Do fato anterior se levanta a necessidade de trabalhar na agenda da saúde bucal coletiva a dieta na alimentação, isto é, buscar políticas e estratégias queridas, desejadas pela população para adaptar estilo de vida alimentar mais saudável. Isto inclui distribuição melhor do alimento que dá vida, energia barata para a população, sobretudo a faminta. Uma nutrição saudável deverá exercer pressão nos comerciais de televisão, no próprio esforço de evitar seu consumo pelos efeitos prejudiciais que trazem à sociedade.

O seguinte problema, relacionado com a agenda de saúde bucal é a educação em saúde, parte essencial da promoção da saúde, e importantes para o início, continuidade e sucesso da agenda, que também consiste na realização de ações preventivas de saúde bucal para resolver o problema da placa dento-bacteriana e o fortalecimento da população sadia através do flúor. O fator ambiental é o mais importante; logo, toda a sociedade deve compreender a necessidade e os benefícios da fluoretação das águas de consumo humano.

As ações preventivas requerem adequada informação, para que os construtores da agenda de saúde e de saúde bucal coletiva, possam compreender a abrangência das mesmas e o impacto social que se deseja. Desta forma o Conselho Local de Saúde deve ser provido das informações oportunas e eficazes nesta ação. Porque é na mudança na reprodução das condições objetivas e subjetivas do estilo de vida que se radica o sucesso da educação em saúde bucal, o que deve ser discutido na agenda saúde bucal com a sociedade, isto é, definir os nossos comportamentos e a ética dos mesmos, em relação à liberdade de sentimento, expressão e ação.

A terceira ação da agenda constitui o trabaIho social de reunir população, trabalho com famílias, grupos sociais, movimentos sociais para reforçar alianças por um estilo de vida coletiva mais saudável.

Esta agenda requer da consciência do agente de saúde bucal e da consciência social para "indignar-se" com a falta de respeito ao trato massificado do estomatológico como problema de saúde pública e não somente bucal, pois também gera problemas psicológicos, biológicos e outros.

Num trabalho coletivo, a negociação, o acordo ou "contrato" consciente de mútuas ações para buscar esta saúde é um trabal ho a ser desejado. É uma negociação coletiva inicialmente com o Conselho Local de Saúde, para em seguida buscar adesão nos outros espaços sociais da rede de serviços de saúde.

A política que encoraja a saúde bucal coletiva com hábitos saudáveis através de uma ação coletiva ou social é mais ética e praticável ou possível do que concentrar os esforços sobre a saúde na responsabilidade individual (Sheiham, 1973).

Em todo caso, uma vez definidos de forma participante, os hábitos ou comportamentos a 
serem transformados, deve considerar-se que aquele comportamento, hábito de mudança no estilo de vida, é consistente com a cidade saudável e com o que o ser humano quer, como indivíduo, cidadão e como totalidade social.

$\mathrm{O}$ anterior requer condicionar a uma resposta concordada para a intervenção coletiva e individual com aceitação de novas informações e novas estruturas no estilo de vida. Porque se a população acredita nos danos prejudiciais à saúde bucal e reflete sobre eles, seguramente estará mais disposta a aceitar e agir sobre novas formas de estilo de vida e comportamento, o que tem a ver com a valorização (ideologia) da vida e da saúde e a confiança numa ação de construção da mesma, conhecendo os passos de todo o processo a ser seguido para conseguir as metas definidas.

Daí a importância de estabelecer a credibilidade no agente de saúde bucal coletiva como comunicador, desenvolvendo novos vínculos, relações entre os trabal hadores da saúde e a população, utilizando o próprio exemplo, com demonstrações objetivas, sobre a própria realidade e refletidas para tomar consciência delas, verificando "pelos próprios olhos" (o olhar comunitário é muito sábio neste sentido) a eficácia dos procedimentos ofertados, discutidos e persuadidos.

As melhores experiências indicam a utilização de trabalho de grupo, oficinas de criação com multiplicadores de saúde (De Moura \& Santos, 1994), em vez de palestras de conteúdo complexo e sem comunicação efetiva, sem vínculo e sem responsabilidade na continuidade do processo. Em todo caso evitar, quanto possível, a introdução do medo ou repressão nos processos acordados, mobilizando mais pela persuasão democrática do que pela ditadura das comunicações que somente podem levar à alienação.

Desta forma, atuando solidariamente com a população, pode-se evitar o estímulo da propaganda perniciosa à saúde, especialmente na alimentação, na tel evisão, controlando e obrigando os produtores a informar sobre os conteúdos dos alimentos nas etiquetas e anúncios, conjuntamente com chamados de atenção sobre o prejuízo que pode ser causado na saúde bucal de uma coletividade, e a possibilidade do risco de adoecer, intervindo na mídia para garantir ao consumidor o seu direito a uma vida saudável, a uma nutrição adequada e a uma higiene continuada.

A participação com autodeterminação e co-responsável da coletividade na identificação, prevenção e solução dos problemas bucais introduz a diferença fundamental com qualquer outra intervenção, desde que esta seja gerada na própria coletividade numa ação dialógica e de intercâmbio de saberes, com protagonistas ativos no esforço comum de gerar e manter a saúde de um determinado espaço social-território.

Resta propor para formação dos agentes de saúde bucal coletiva entendidos como educadores numa "mediação social", extrapolando o limite histórico de difundir, reproduzir ou simplesmente serem informadores sobre as questões da saúde que interessam aos poderosos, desenvolverem capacitação continuada no estudo da ideologia e política (Estado) dominantes e a sociedade civil com sua estrutura e organização, como das ações que nela desenvolvem os movimentos populares; aprendizagem e prática da pesquisa participante sobre questões fundamentais da realidade, na que se supõe vai trabalhar, e no sentido orgânico, realizar-se profissional, ética e politicamente.

Que o recurso humano odontológico seja visto como ativo participante da equipe de saúde bucal, da equipe da saúde na formação da agenda da saúde bucal coletiva, enquanto atuação técnica e enquanto "mediação social", como forma de intervenção social que integra uma prática coletiva e uma individual, uma biotécnica e uma social, uma burocrático-administrativa e uma política. 


\section{Referências}

CECíLIO, L. C., 1994. Inventando a Mudança na Saúde. São Paulo: Hucitec.

CORDEIRO, H., 1996. O PSF como estratégia de mudança do modelo assistencial do SUS. Cadernos Saúde da Família, 1:10-15.

CORDÓN, J., 1996. Dificuldades, contradições e avanços, na inserção da odontologia no SUS. Revista Divulgação em Saúde para Debate, 13:36-53.

CUSHING, A. M.; SHEIHAM , A. \& M AIZELS, J., 1986. Developing socio-dental indicators - The social impact of dental disease. Community Dental Health, 3:3.

DE MOURA, F. M. \& SANTOS, M. S. S., 1994. Saúde Bucal: uma Proposta para Formação de Agentes Multiplicadores - Um Estudo de "Caso" para a Cidade Satélite de Paranoá. Brasília: Universidade de Brasília, Faculdade de Ciências da Saúde/ Departamento de Odontologia, Curso de Especialização em Odontologia em Saúde Coletiva. $160 \mathrm{pp}$.

FOLHA DE SÃO PAULO, 1996. Adolescente come como naTV. Folha deSão Paulo, 9/9:10

GENRO, T., 1996. O novo espaço público, 21 teses para a criação de uma política democrática e socialista. Folha deSão Paulo, MAIS!, 9/6:3.
GIES, W. J., 1926. Dental Education in the United States and Canadá. New York: Carnegie Foundation for the advancement of teaching, Bulletin 19.

MENDES, E. V., 1996. Uma Agenda para a Saúde. São Paulo: Hucitec.

MENDES, E. V., 1993. Distrito Sanitário. O Processo Social de Mudança das Práticas Sanitárias do Sistema Ú ni co de Saúde. São Paulo/Rio de Janeiro: Hucitec-Abrasco.

MURRAY, B. P. \& WIRSE, H. J., 1975. Satisfaction with care and the utilization of neighborhood health center. Journal of Public Health Dentistry, 35:170.

REISINE, S. T., 1981. Theoretical considerations in formulating sociodental indicators. Social Science \& Medicine, 15A:745-750.

SHEIHAM, A., 1973. An evaluation of the success of dental care in the United Kingdom. British Dental Journal, 135:271-279.

SHEIHAM, A., 1992. The role of dental team in promoting dental health and general health trough oral health. International Dental Journal, 42:223228.

SHEIHAM, A. \& CROOG, S. H., 1981. The psyco-social impact of dental diseases on individuals and communities. Journal of Behavioral Medicine, 4:257. 